INTERNATIONAL DESIGN CONFERENCE - DESIGN 2018

https://doi.org/10.21278/idc.2018.0433

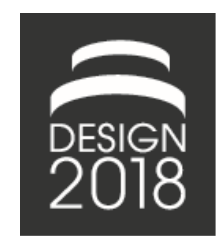

\title{
AN INITIAL PROTOTYPE OF A TOOL FOR DEFINING VALUE PROPOSITION IN THE PRODUCT-SERVICE SYSTEM (PSS) DESIGN
}

\author{
S. d. C. Fernandes, M. Rosa, C. Queiroz and H. Rozenfeld
}

\begin{abstract}
The design of product-service systems (PSS) requires a complete reformulation of the company's business model. A central aspect of business models is the value proposition, which is commonly created with tools such as the Value Proposition Canvas (VPC). However, problems were identified during the application of the VPC in the context of a PSS design. This work aims to create and test an initial prototype of a value proposition tool for PSS. Both tools were submitted to controlled experiments, providing an evaluation of the VPC's problems and insights for further development of the new tool.
\end{abstract}

Keywords: product-service systems (PSS), design tools, service oriented design

\section{Introduction}

Product-service systems (PSS) have been continually developed by companies as solutions that are capable of adding value and fulfilling customers' desires and needs (Boehm and Thomas, 2013). This terminology refers to solutions that combine products and services in the shape of systems, preferably offering products-as-services, resulting into offerings that may be oriented to the usage of the product or to the results that the solution can offer (Baines et al., 2007; Neely, 2008; Annarelli et al., 2016).

The design community has been providing a wide support for spreading the PSS concept by developing design tools, methodologies and process models that aim to support the design of a PSS or the transition of product providers towards providing PSS, i.e., the servitization process (Moser et al., 2015; Pieroni et al., 2016; Zhang et al., 2018). One characteristic of PSS that highly influences the related design techniques and process models is the fact that developing a PSS requires a transformation of the entire business model, since all main dimensions of the business model, such as key activities, resources, channels, value proposition, among others, will probably be submitted to modifications.

There are several models for representing the business model of a solution, e.g. Business Model Canvas (Osterwalder and Pigneur, 2010), while some of them are focused on representing PSS business models (Barquet, 2015). All business model representation tools are characterized by some common aspects, such as presenting the value proposition as their central point.

The value proposition is the "implicit promise that a firm makes to its customers to provide a combination of values which links two different visions of value: internal and external" (Gilles and Christine, 2016). Developing a value proposition is a laborious process. It requires fully understanding the customers and other stakeholders in order to design a solution that really provides internal and 
external value. Due to the complexity of the value proposition design, the Business Model Canvas is complemented by the Value Proposition Canvas (Osterwalder et al., 2014).

This research is part of a broader development project of a servitization framework (Pieroni et al., 2016) with the intent of transforming product-oriented manufacturers into PSS providers and designing complete PSS solutions. This framework integrates tools and methods that may be configured and adapted in order to support the iterative creation of the following main deliverables:

- business analysis of the current situation (in case of existing business) or analysis of market and opportunities (in case of new business) in order to define strategies and challenges of the servitization/PSS design process;

- the new value proposition;

- business model and business case for this value proposition;

- integrated solution architecture, which comprises product architecture, service/business process architecture, and infrastructure architecture (which contains the information and communications technology (ICT) architecture);

- the detailed business design (it includes detailed design of the elements defined in the architecture and a roadmap to implement or modify them).

Based on those deliverables, the PSS is implemented and launched, in which the complete bundle of running elements is called "launch". The deliverable "operation" indicates the elements that support the PSS middle-of-life. Those elements may be modified and improved as needed or requested by the stakeholders during the PSS lifecycle. "End-of-life" (EOL) represents the deliverables that support the EOL strategy designed for the PSS, which might contain, for example, systems, assets and trained people for remanufacturing the PSS hardware, among others.

The value proposition is an important deliverable of the framework since all other deliverables are related to it. For proposing the value proposition, several tools and methods from literature have been used in the servitization framework. However, some problems were identified specifically when applying the Value Proposition Canvas. Those problems are approached more deeply in section 2.

The goal of this research is to propose a prototype of a new value proposition tool that is compatible with the servitization framework and that solves the problems that were identified in the applications of the Value Proposition Canvas. This publication reports the first steps carried out to create and test the prototype, which was compared to the Value Proposition Canvas. The tool was named as "Value Ring" because it is an iterative tool and its central element is the representation of a diamond containing the elements of value that the solutions can satisfy based on the stakeholders' profile.

This paper is structured as follows. Section 2 presents a description of the Value Proposition Canvas and the problems identified during its application in the context of the servitization framework. Section 3 presents the research methodology. The main findings and discussions are presented in section 4 . Lastly, section 5 presents the final remarks.

\section{The Value Proposition Canvas}

The Value Proposition Canvas is a tool proposed by Osterwalder et al. (2014) for defining the solutions to be offered to customers. The tool requires the definition of a customer segment and the identification of the "customer jobs", pains and gains in order to create products and services and define its "pain relievers" and "gain creators". An overview of the Value Proposition Canvas is provided by Figure 1 accompanied by a brief description of each one of its main elements.

On the right side of the Value Proposition Canvas, the customer segment gets detailed. On that part, "customer jobs" stand for what the customers want to achieve in their lives or in their work, what may also include the problems they are trying to solve or their needs. Pains are the problems, obstacles, risks or any other undesired outcome that annoys the customer when performing a customer job or anything that does not allow the customer to fulfil the job. Gains are the outcomes or benefits that are positive to the customer, possibly being required, desired, expected or unexpected by the customer. 


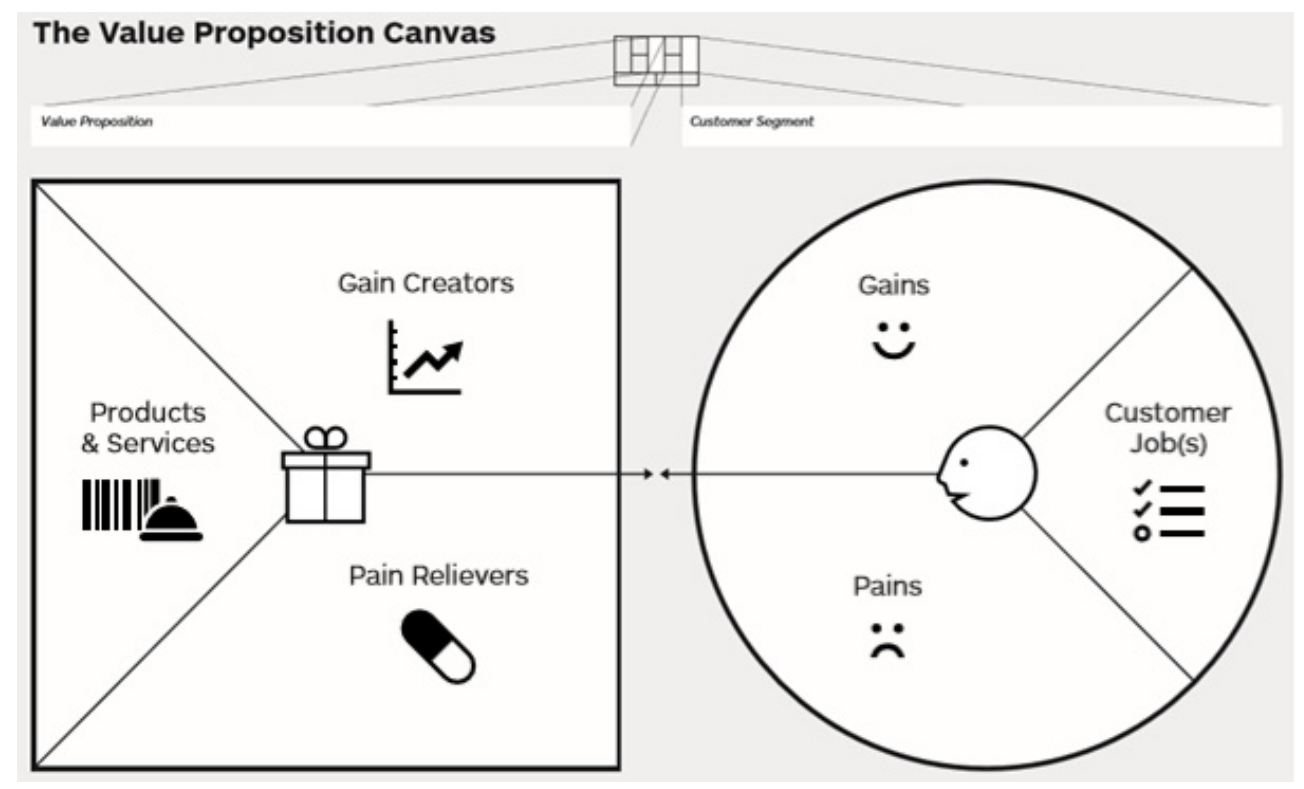

Figure 1. The Value Proposition Canvas (Osterwalder et al., 2014)

On the left side of the Value Proposition Canvas, the value proposition gets detailed. Products and services stand for tangible or intangible solutions that compose the value proposition. Osterwalder et al. (2014) define as "pain relievers" the characteristics of products and services that act to relieve or fulfil the customers' pains. In contrast, "gain creators" are the characteristics of the products and services that provide the customers' gains.

A brief description of the process required by the Value Proposition Canvas according to Osterwalder et al. (2014) is illustrated in Figure 2. The success of the application of this process is mainly related to listing products and services, where creativity techniques may be employed.

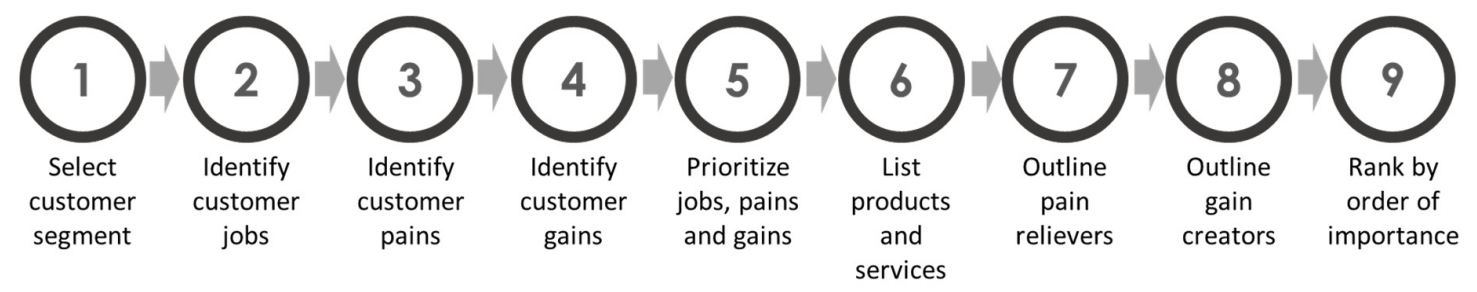

Figure 2. Process for using the Value Proposition Canvas (adapted from Osterwalder et al. 2014)

The Value Proposition Canvas was employed to support some applications of the servitization framework. However, several practitioners provided negative feedback during its applications, highlighting the amount of redundant information and problems on how to classify data. Actually, it may be confusing to identify what information should be classified as a "customer job", a gain or a problem when translating the customers' speech. For example, suppose that a team is developing a value proposition based on a customer's needs. On an interview, this customer stated that he wants a cell phone because he needs to make phone calls. In this situation, making a call could be a "customer job". However, one example of a possible required gain proposed by Osterwalder et al. (2014) is exactly that a cell phone must be able to make calls. The classification process of this tool can be considered ambiguous. The same information ("make a call") might be required in many moments of the tool application (steps of the process - Figure 2). Thus, the Value Proposition Canvas was not considered intuitive by some practitioners during the application of this tool.

Besides, the first step of fulfilling the Value Proposition Canvas requires selecting a customer segment. However, when the goal is to develop a PSS, one of the most important enablers is partnership (Morelli, 
2006). It is not wise nor recommended to take only the customers into consideration. Yet, the Value Proposition Canvas focuses on the customers, leaving partners' and other stakeholders' interests out of focus.

\section{Methodology}

This work follows a qualitative approach for analysing the applicability of the Value Proposition Canvas in order to propose a prototype for a new tool on the context of PSS design following the servitization framework initially proposed by Pieroni et al. (2016). Since prototypes are well-known in the design field as effective learning tools, a designerly methodological approach (Cross, 2006) was followed by creating a new value proposition tool. The prototype of the new tool was initially applied with experts and, after, it was compared to the Value Proposition Canvas by means of the users' evaluation.

Therefore, the methodology of this work was divided into the following steps:

1. Selection of tools and methods for supporting the problem solving of issues of the Value Proposition Canvas.

2. Creation of the first prototype of a new value proposition tool.

3. Test and identification of problems related to both tools by means of a comparison.

Those steps are described in the following subsections.

\subsection{Selection of tools and techniques for supporting the problem solving of issues of the Value Proposition Canvas and creation of the first prototype of a new value proposition tool}

A literature review was performed to identify tools and knowledge that could support the problem solving of the issues identified in the Value Proposition Canvas and also to identify tools and knowledge that could be employed on the creation of the new value proposition tool.

The creation of the new value proposition tool, named as "Value Ring", was performed by the authors, adapting the Value Proposition Canvas according to the problems that were previously identified and including the tools and knowledge that were selected as useful. The elements that were considered ambiguous in the Value Proposition Canvas were excluded on the creation of the new tool.

It is important to highlight that the intention of the first version of the value proposition tool was to achieve a prototype that would be tested by users. In order to make it applicable to the tests, a poster and cards explaining the process of application were created.

\subsection{Test and identification of problems related to both tools by means of a comparison}

This step of the research methodology aims to test the prototype of the new value proposition tool in order to verify its effectiveness and identify problems of both the Value Proposition Canvas and the Value Ring by means of a comparison. To achieve the goals of the test, a case study was performed in a controlled experiment with 10 researchers in the fields of product and PSS design. This experiment lasted three hours. It had two main objectives: to identify the obstacles related to usability of both tools and to identify if the tools were applicable to the value proposition of a PSS design.

The experiment was based on a previous case study of the servitization framework (Pieroni et al., 2016), which was performed by a manufacturer of image diagnosis equipment, hereinafter called MedCo. MedCo is a market leader in their customer segment, providing equipment to diagnostic centres. They intended to enlarge their market share by approaching a new customer segment - the doctors. However, their equipment was too expensive, and doctors were not able to afford MedCo's machines. By employing the servitization framework, they intended to reduce the investment costs for doctors and to design a solution that could fulfil their needs and expectations. Based on this case, the participants of the case study were asked to develop value propositions that could allow MedCo on achieving the doctors as a new customer segment.

Based on this case, a list of problems, opportunities, needs, and desires of three core stakeholders (the patient, the doctor and MedCo itself) was provided. The participants were asked to develop a value proposition that could fulfil, at least in part, this list. A brief familiarization about the Value Proposition Canvas and about the Value Ring was presented to all participants. Cards explaining each step of the 
application of both tools were also provided. The cards related to the Value Proposition Canvas had exactly the same content provided by Osterwalder et al. (2014). The participants were divided into 4 groups and the groups were placed in two distinct rooms. In room 1, two groups started the experiment by receiving basic instructions about the Value Proposition Canvas, as well as the poster and cards that explained each step. Then, they started filling out the tool. This first stage lasted about one hour and a half. Then, the same experiment was performed with the Value Ring, which also lasted one hour and a half. In room 2, other two groups employed the same tools in a different order in order to avoid bias (i.e., at first, they performed the experiment with the Value Ring and then with the Value Proposition Canvas).

After the application of each tool, each participant answered a questionnaire, which was developed based on the method proposed by Echeveste et al. (2007) for structuring research protocols. The questionnaire was divided into two sections. The first section contained five questions with answers distributed in the Likert scale, varying from 1 (completely disagree) to 5 (completely agree). Justifications were asked from the respondents if they found it necessary. The second section contained four questions that required an open answer. At the end of the experiment, all participants were asked which of both tools they would select if they needed to design a value proposition in the future.

In order to evaluate the degree of concordance among respondents on the questions answered with the Likert scale, we calculated the interrater reliability (IRR). This index may reach a maximum value of 1 , where "one" stands for complete concordance among answers. In this research, a minimum interrater reliability coefficient of 0,5 is required to consider that the respondents achieved a consensus. We adopted the interrater coefficient called "within-group" since the respondents are considered as a statistical group (Echeveste et al., 2007).

For each question to be evaluated (represented as $X_{J}$ ) the interrater within-group coefficient (represented as $\left.r_{w g(1)}\right)$ is calculated by means of Equation 1 (James et al., 1984),

$$
r_{w g(1)}=1-\left(\frac{s_{X_{J}}{ }^{2}}{\sigma_{E U^{2}}}\right)
$$

where $s_{X_{J}}$ is the observed standard deviation, and $\sigma_{E U}$ is the deviation expected in case all judgments were due to random measurement error. The observed standard deviation $\left(s_{X_{J}}\right)$ is calculated with Equation 2 (James et al., 1984),

$$
s_{X_{J}}=\frac{\sum_{1}^{K}\left(x_{i}-\bar{X}\right)^{2}}{K-1}
$$

where $K$ is the number of respondents, $x_{i}$ is the value of the answer of the respondent to one single item $X_{J}$, and $\bar{X}$ is the average of all respondents' answers to one single item $X_{J}$. Finally, the expected standard deviation $\left(\sigma_{E U}\right)$ is calculated with Equation 3, assuming a uniform distribution (James et al., 1984),

$$
\sigma_{E U}^{2}=\frac{\left(A^{2}-1\right)}{12}
$$

where $A$ is the number of alternatives in the score scale (i.e., 5 alternatives).

The open questions and the justifications provided by the respondents were synthesized in order to achieve further conclusions.

\section{The Value Ring tool}

The Value Ring aims to support design teams (i.e. the tool's users) on creating PSS value propositions. It was created in order to attempt to solve some problems that were identified in the application of the Value Proposition Canvas in the context of the servitization framework. The problems are presented below:

1. Lack of the perspective of stakeholders;

2. Excessive amount of redundant information and consequent confusion on classifying data as customer jobs, gains or pains.

In order to establish a clear perspective of the goals of the value proposition, the Value Ring requires a pre-established "challenge", i.e., the main objective of creating a new value proposition. The 
servitization framework employs design thinking methods for creating empathy with stakeholders. Therefore, the challenge was framed on the shape that is usually proposed by this approach - as a "how might we" question based on a major problem, need or opportunity being pursued.

For dealing with problem 1, a field called "stakeholders' profile" was established. There, all information that was retrieved from observation and interviews with the selected stakeholders would be placed. It would support people in understanding the most important stakeholders. In order to keep their information separated, it is possible to employ different post-it colours for each stakeholder. Also, for dealing with problem 1, the stakeholders' profile was divided into 2 categories, differently of the Value Proposition Canvas that divides the customers' (not stakeholders') profile into 3 categories. One of them would receive only "positive" quotes from the stakeholders, i.e., their needs, possible opportunities, insights, and desires. The other category would receive the "negative" quotes, i.e., problems, obstacles, and risks.

In order to deal with problem 2 and to make the value proposition clearer, we employed the elements of value proposed by Almquist et al. (2016). The elements of value are basically the fundamental benefits that an offering may provide, such as quality, risk reduction, wellness, among others. Almquist et al. (2016) were based on the Maslow's hierarchy of needs by proposing those elements of value in the shape of a pyramid that is divided into four categories: functional, emotional, life-changing, and social impact. The elements of value are illustrated in Figure 3.

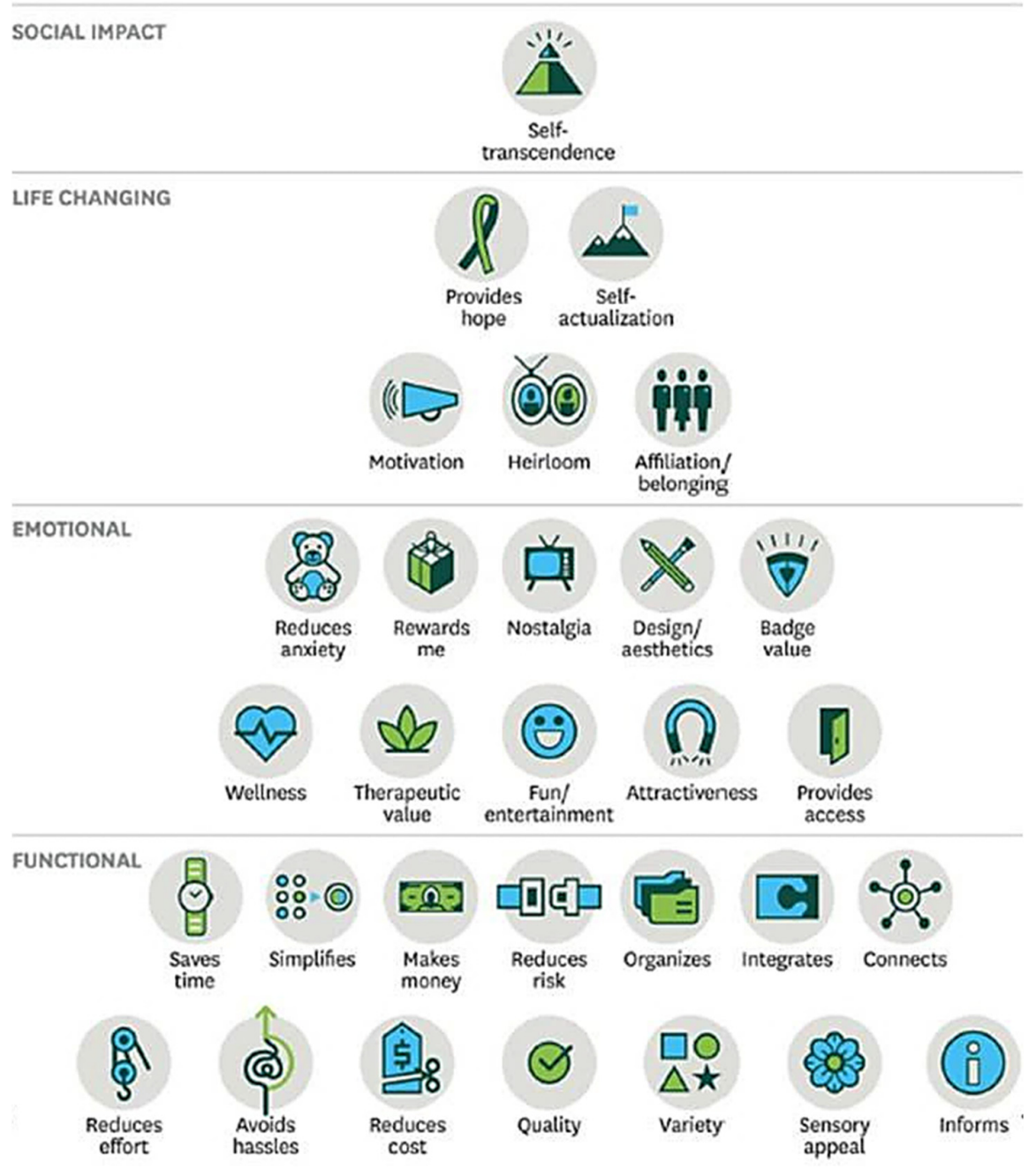

Figure 3. Elements of value (Almquist et al., 2016) 
Those elements of value are an opportunity for summarizing what, essentially, a set of needs means to the stakeholder. For example, if the solution provider is spending too much in maintenance, and the customers are complaining too much about the excess of time that the machine is not working due to broken parts, it means that one value element that is lacking in their current solution is "Quality". Besides, it is also useful for describing more directly what value the solution provides to each stakeholder. Therefore, by employing the elements of value, it would be no longer necessary to describe the gain creators or pain relievers from the Value Proposition Canvas. Instead, the list of products and services would need to be complemented by the main characteristics/features of products and services that provide the elements of value that were identified as required by the stakeholders.

Another aspect that should be pointed out is that the Value Ring was conceived to be employed in the context of the servitization framework. Therefore, it must be preceded by some activities that are essential to fill the tool. The recommendation is to follow a sequence of techniques, such as interviews, observation, empathy and journey maps, among others, in order to collect all important information, as exemplified in Figure 4. Furthermore, it is essential to fully comprehend the company's context and to generate empathy with the stakeholders that are impacted by the solution.

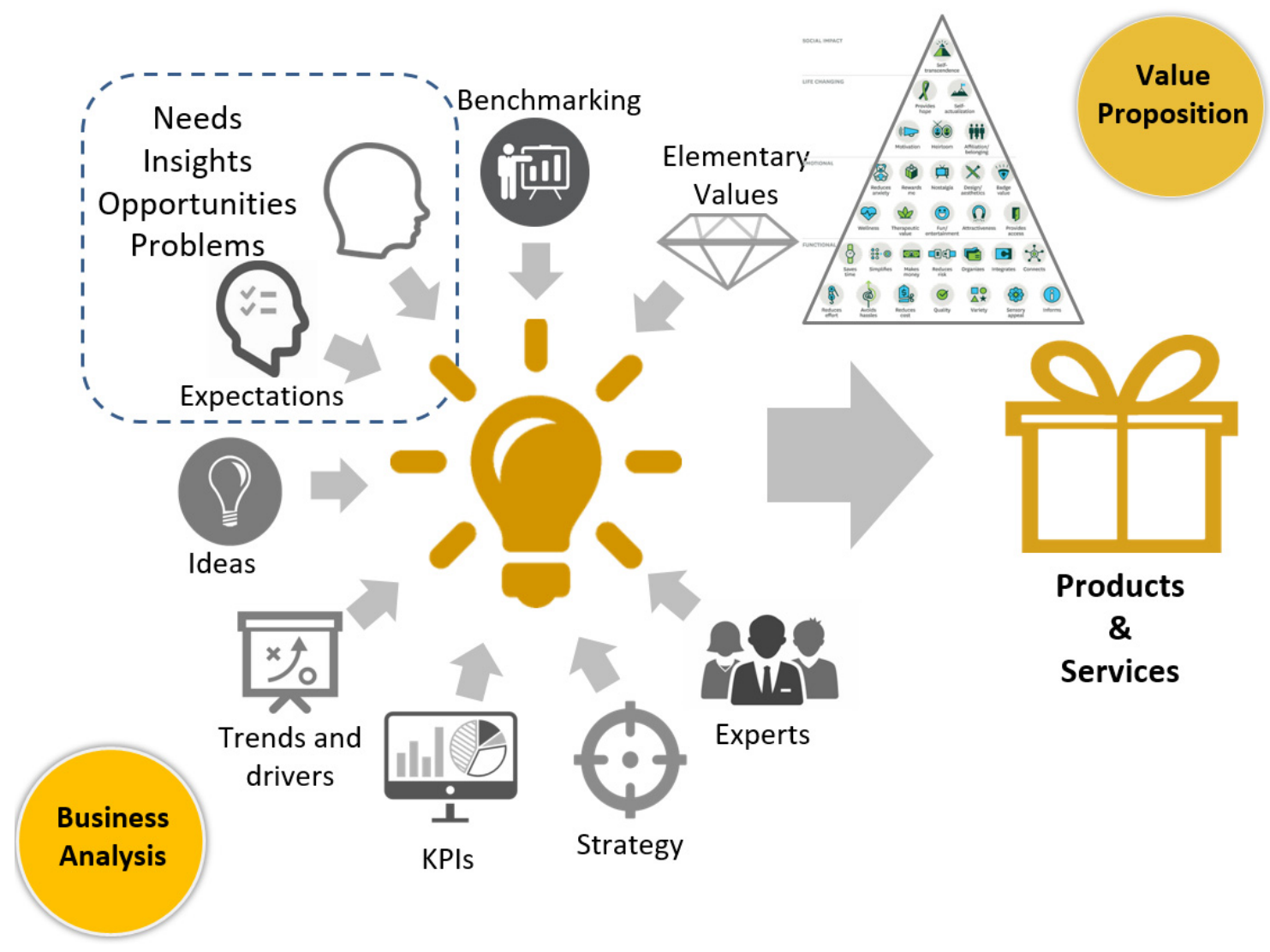
Figure 4. Information that should be collected for fully understanding the current business model and generating empathy with the stakeholders (created by the authors)

In the experiment of this work, a summary of the results of the stakeholders' observation stage was provided to the participants in order to allow the experiment to be performed in a short timeframe. However, in a real application, the Value Ring may be employed only after all relevant information is collected. The structure of the prototype of the Value Ring is illustrated in Figure 5. 


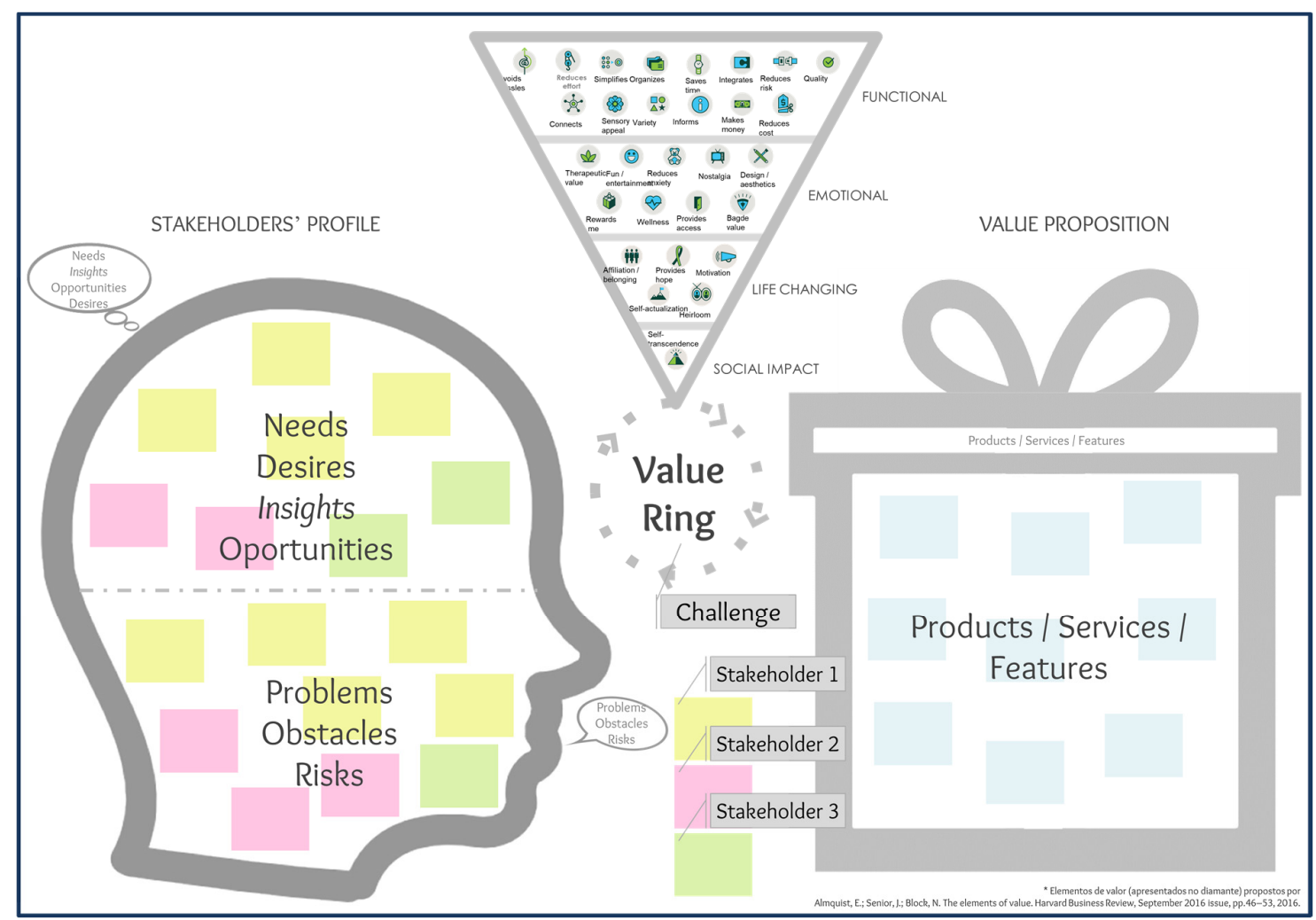

Figure 5. The Value Ring (created by the authors)

The steps that should be followed to employ the Value Ring are illustrated in Figure 6.

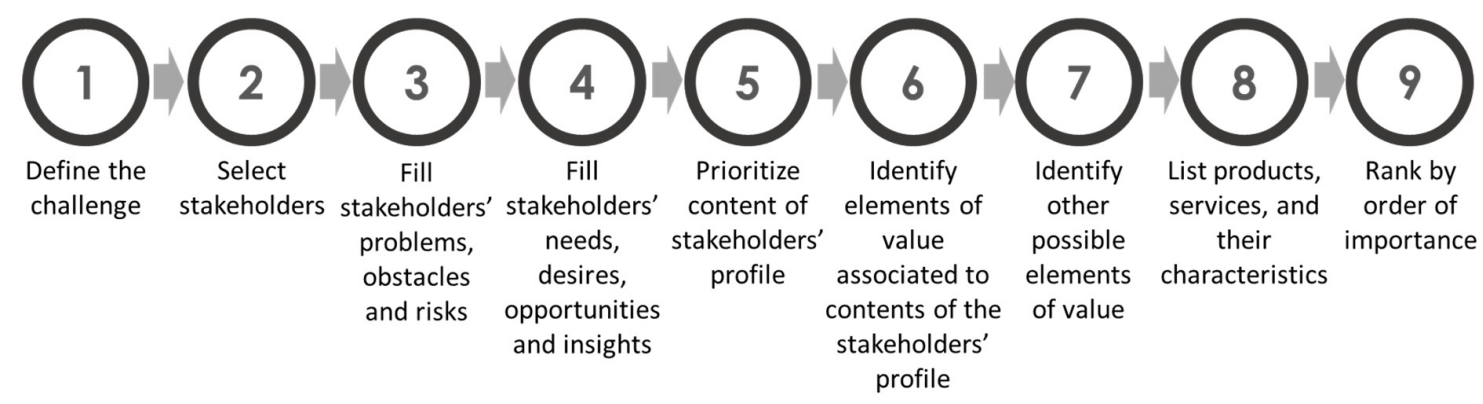

Figure 6. Process for using the Value Ring (created by the authors)

First of all, a challenge must be well defined in the shape of a "how might we" question. For example, "how might we change our solution so that doctors can afford it?". In step 2, the left side of the Value Ring starts to get filled. The most important stakeholders related to the challenge must be selected and listed on the right side of the stakeholders' profile. Based on interviews and observation of those stakeholders, in step 3 all problems must be listed on the lower part of the stakeholders' profile. Then, in step 4, all needs, desires, opportunities, and insights must be listed on the upper part of the stakeholders' profile. It is recommended to use different post-it colours for each stakeholder. In step 5, the stakeholders' profile should have its content prioritized, in order to focus on the most relevant needs, opportunities, insights, and problems.

Step 6 starts the procedure with the elements of value. All information that was prioritized should be analysed in comparison with the elements of value in order to identify what elements of value are required by the solution. Step 7 identifies other elements of value that could be offered by the solution and that could aggregate value based on the team's understanding of the stakeholders. Both steps 6 and 7 are supported by cards that explain each element of value and provides examples. 
On step 8, the right side of the Value Ring starts to get filled. All ideas of products, services, and features that provide the elements of value by fulfilling the needs of the stakeholders and solving their problems must be listed in the space provided for products, services, and features. Usually, this step is commonly performed with the support of creativity techniques. However, in the test, we suggested to participants to create ideas based on their discussion. Finally, on step 9, those solutions should be ranked by order of importance.

\section{Test results and discussion}

This section presents the results of tests conducted with the Value Proposition Canvas and the Value Ring as explained in section 3.2.

The answers to the questionnaire were statistically analysed according to the interrater reliability coefficient and the final values are presented in Table 1.

Table 1. Results of the conducted tests (created by the authors)

\begin{tabular}{|c|c|c|c|c|}
\hline & \multicolumn{2}{|c|}{$\begin{array}{l}\text { Value Proposition } \\
\text { Canvas }\end{array}$} & \multicolumn{2}{|c|}{ The Value Ring } \\
\hline & $\bar{X}$ & $r_{w g(1)}$ & $\bar{X}$ & $r_{w g(1)}$ \\
\hline $\begin{array}{l}\text { I was able to understand the complete procedure of } \\
\text { employing the tool. }\end{array}$ & 4,78 & 0,90 & 3,70 & 0,22 \\
\hline I think that the tool was easy to use. & 4,44 & 0,86 & 3,50 & 0,31 \\
\hline $\begin{array}{l}\text { I think that there is no or there is little redundancy on } \\
\text { the information required by the tool. }\end{array}$ & 3,00 & 0,00 & 3,78 & 0,03 \\
\hline $\begin{array}{l}\text { I think that every information that was needed to } \\
\text { develop a value proposition was required by the tool. }\end{array}$ & 3,89 & 0,57 & 3,60 & 0,20 \\
\hline $\begin{array}{l}\text { I think that the steps proposed by the tool follow a } \\
\text { logic order compatible with my reasoning process. }\end{array}$ & 4,78 & 0,90 & 3,90 & 0,28 \\
\hline
\end{tabular}

As illustrated in Table 1, most respondents agreed or completely agreed that the Value Proposition Canvas was an easy tool, both to use and to understand. They also agreed or completely agreed that its logic was clear and compatible with their reasoning process. The only aspect that had no agreement was the aspect of redundancy. It does not lead to a clear conclusion about the excess of redundancy of information in the Value Proposition Canvas since the IRR coefficient does not meet the criteria established by this work and the average answer is 3,00. However, it corroborates that other users also feel that there is much redundancy since $50 \%$ of the respondents answered that they partially or completely disagree that there is no or little redundancy of information in this tool.

Referring to the Value Ring, in general, the participants disagreed more among themselves on their answers when compared with the Value Proposition Canvas. But, even though the average answer on lack of redundancy is better on the Value Ring, it is not possible to reach a clear conclusion about its usability due to the IRR coefficient.

Both tools were capable of generating products and services solutions, achieving an average of about three solutions per group. The difference was not meaningful enough to reach a conclusion on this aspect.

In the end, 6 respondents stated that, if they needed to design a value proposition again, they would select the Value Proposition Canvas, while 3 of them preferred the Value Ring. One of the respondents did not answer this question.

The greatest difficulties that were reported by the respondents regarding the Value Proposition Canvas were difficulty in prioritizing jobs, pains, and gains; confusion on separating jobs, pains and gains; and repetitive information. However, in contrast, some respondents highlighted the fact that there is redundant information as one of the advantages of the Value Proposition Canvas since it would reinforce 
what is really important to the customer. Some respondents also stated that the Value Proposition Canvas was easier to use, more direct, and dynamic, stating that the reasoning logic is appropriate and easier.

The greatest difficulties related to the Value Ring were the employment of the elements of value, being criticized by 4 of the respondents. The prioritization of content from the stakeholders' profile was another difficulty that they reported. A few respondents also stated that creating a value proposition was harder with the Value Ring. However, the greatest advantage that was pointed out is the fact that it focuses on stakeholders, and not only on the customer. Respondents also stated that the definition of a design challenge provides better guidance to the reasoning pattern. There were respondents that also pointed out the elements of value as an advantage, even though it was not as many as the respondents who pointed out as a difficulty.

The problem of lack of stakeholders' perspective with the Value Proposition Canvas was solved by the Value Ring, being pointed out as an advantage of the tool. This aspect should be kept on a new version of the tool. Finally, one of the problems that were initially identified (excessive amount of redundant information) should be further investigated, since some respondents pointed out this aspect as an advantage instead of a problem.

A summary of this discussion is presented in Table 2, relating the results with the goals that structured the questionnaire.

Table 2. Summary of tests results (created by the authors)

\begin{tabular}{|c|c|c|}
\hline Goals & Value Proposition Canvas & The Value Ring \\
\hline $\begin{array}{l}\text { Verify the ease of } \\
\text { understanding the tool }\end{array}$ & $\begin{array}{l}\text { Partially or completely agree that the } \\
\text { tool is easy to understand }\end{array}$ & Inconclusive results \\
\hline $\begin{array}{l}\text { Verify the ease of use of the } \\
\text { tool }\end{array}$ & $\begin{array}{l}\text { Partially or completely agree that the } \\
\text { tool is easy to use }\end{array}$ & Inconclusive results \\
\hline $\begin{array}{l}\text { Verify the amount of } \\
\text { redundancy of information in } \\
\text { the tool }\end{array}$ & Inconclusive results & Inconclusive results \\
\hline $\begin{array}{l}\text { Verify the lack of information } \\
\text { in the tool }\end{array}$ & $\begin{array}{l}\text { Nor agrees nor disagrees or partially } \\
\text { agrees that the tool does not lack } \\
\text { information }\end{array}$ & Inconclusive results \\
\hline $\begin{array}{l}\text { Verify if the logical order of } \\
\text { the step-to-step procedure is } \\
\text { compatible with the } \\
\text { participants' reasoning process }\end{array}$ & $\begin{array}{l}\text { Partially or completely agree that the } \\
\text { logical order of the step-to-step } \\
\text { procedure is compatible with the } \\
\text { participants' reasoning process }\end{array}$ & Inconclusive results \\
\hline $\begin{array}{l}\text { Identify the greatest difficulties } \\
\text { of the tool }\end{array}$ & $\begin{array}{l}\text { - Prioritizing jobs, gains, and pains } \\
\text { - Confusion on separating jobs, gains, } \\
\text { and pains } \\
\text { - Repetitive information }\end{array}$ & $\begin{array}{l}\text { - Employment of elements of value } \\
\text { - Prioritizing information on the } \\
\text { stakeholders' profile } \\
\text { - Achieving a final value proposition }\end{array}$ \\
\hline $\begin{array}{l}\text { Verify the capacity of } \\
\text { generating solutions of } \\
\text { products and services }\end{array}$ & $\begin{array}{l}\text { Capable of generating products and } \\
\text { services }\end{array}$ & $\begin{array}{l}\text { Capable of generating products and } \\
\text { services }\end{array}$ \\
\hline $\begin{array}{l}\text { Verify the number of solutions } \\
\text { generated by employing the } \\
\text { tool }\end{array}$ & About 3 solutions per group & About 3 solutions per group \\
\hline $\begin{array}{l}\text { Identify the greatest advantages } \\
\text { of the tool }\end{array}$ & $\begin{array}{l}\text { - Easy to use } \\
\text { - Direct and dynamic } \\
\text { - Good logic process }\end{array}$ & $\begin{array}{l}\text { - Focus on stakeholders (not only } \\
\text { customers) } \\
\text { - Definition of a challenge } \\
\text { - Elements of value }\end{array}$ \\
\hline
\end{tabular}

\section{Conclusions and future work}

The goal of this research is to propose a prototype of a new value proposition tool that is compatible with the servitization framework and that solves the problems that were identified in the applications of the Value Proposition Canvas. Based on a list of initial problems that were already identified on the 
application of the Value Proposition Canvas, a new prototypical tool was created and named as Value Ring. Considering the context of the servitization framework, that tool was mainly focused on solving the problems of the Value Proposition Canvas, which are the excessive amount of redundant information among "customer jobs", gains or pains, and the lack of the perspective of stakeholders.

Both tools were tested in a controlled experiment, which provided a new evaluation of the Value Proposition Canvas and improvements that the value ring should be submitted to. The Value Proposition Canvas was considered a tool that is easy to use and understand, resulting in a good usability level. The usability of the Value Ring was not conclusive, pointing out the need of improving it in the following versions of the tool.

One new problem related to the Value Proposition Canvas arose since the respondents pointed out that prioritizing information about the stakeholders on both tools was hard. It indicates that this problem should be approached on a new version of the Value Ring.

The respondents also reported that they found it hard to achieve a value proposition with the Value Ring, indicating particular difficulties in the employment of the elements of value. In a new version of the Value Ring, the use of elements of value may be reviewed or eliminated and a new tool or technique may be identified to replace its usage.

Based on this evaluation, it is possible to conclude that the Value Ring is far from being mature for being employed as an alternative for the Value Proposition Canvas. However, a few of its characteristics may already be aggregated to the Value Proposition Canvas in the context of PSS design, such as taking into consideration the stakeholders' profile instead of only taking the customer into consideration.

Another aspect that should be highlighted is that the Value Ring is in a distinct context. The Value Proposition Canvas is the initial point of defining a new business model, what can be adequate in a case of designers who are already confident with the problem context. However, the Value Ring is in a wider context of integration with the servitization framework and this is why other tools and techniques are required previously to the application of the Value Ring. As explained before, those tools and techniques are essential to fully understand the context of the business and to generate empathy with stakeholders. However, the application of those tools and techniques was not an object of analysis of this publication, since the application of the Value Proposition Canvas and the Value Ring in this publication were based on results derived from interviews and observation of a previous case study. The value proposition tools would not be comparable if they were not based on the same start point.

Future work shall develop an improved version of the Value Ring based on the new problems and insights that were identified with the current test. A further requirements elicitation shall be performed to complement the information derived from the tests. New tests shall also be performed, especially in real cases in the industry.

\section{Acknowledgment}

This work was supported by São Paulo Research Foundation (FAPESP) under the process 2015/23094-6 and 2017/12520-0. The opinions, hypotheses and conclusions or recommendations expressed in this material are responsibility of the authors and do not necessarily reflect the views of FAPESP. The authors would like to extend sincere thanks to São Paulo Research Foundation (FAPESP), Brazilian Counsel for Scientific and Technological Development (CNPq) and the Higher Education Personnel Improvement Coordination (Capes) for supporting this research.

\section{References}

Almquist, E., Senior, J. and Bloch, N. (2016), “The elements of value”, Harvard Business Review, No. September, pp. 46-53.

Annarelli, A., Battistella, C. and Nonino, F. (2016), "Product service system: A conceptual framework from a systematic review", Journal of Cleaner Production, Elsevier Ltd, Vol. 139, pp. 1011-1032. https://doi.org/10.1016/j.jclepro.2016.08.061

Baines, T.S., Lightfoot, H.W., Evans, S., Neely, A., Greenough, R. et al. (2007), "State-of-the-art in product service-systems", Proceedings of the Institution of Mechanical Engineers, Part B: Journal of Engineering Manufacture, Vol. 221 No. 10, pp. 1543-1552. https://doi.org/10.1243/09544054JEM858

Barquet, A.P.B. (2015), Criação De Propostas De Sistema Produto-Serviço No Fuzzy Front-End, p. 287. [online] Available at: http://www.teses.usp.br/teses/disponiveis/18/18156/tde-04052015-101933/pt-br.php. 
Boehm, M. and Thomas, O. (2013), “Looking beyond the rim of one's teacup: A multidisciplinary literature review of Product-Service Systems in Information Systems, Business Management, and Engineering \& Design", Journal of Cleaner Production, Elsevier Ltd, Vol. 51, pp. 245-250. https://doi.org/10.1016/j.jclepro.2013.01.019

Cross, N. (2006), Designerly ways of knowing, Springer London, UK.

Echeveste, M.E., Amaral, C.S.T. and Rozenfeld, H. (2007), “A support tool for the selection of statistical techniques for industrial product development and improvement processes", Complex Systems Concurrent Engineering - Collaboration, Technology Innovation and Sustainability, Springer-Verlag London Ltd, London, pp. 240-248.

Gilles, N. and Christine, L.C. (2016), "The Sustainable Value Proposition of PSSs: The Case of ECOBEL 'shower Head"”, Procedia CIRP, Elsevier B.V., Vol. 47, pp. 12-17. https://doi.org/10.1016/j.procir.2016.03.043

James, L.R., Demaree, R.G. and Wolf, G. (1984), "Estimating within-group interrater reliability with and without response bias", Journal of Applied Psychology, Vol. 69 No. 1, pp. 85-98. https://doi.org/10.1037/00219010.69 .1 .85

Morelli, N. (2006), "Developing new product service systems (PSS): methodologies and operational tools", Journal of Cleaner Production, Vol. 14 No. 17, pp. 1495-1501. https://doi.org/10.1016/j.jclepro.2006.01.023

Moser, U., Maisenbacher, S., Kasperek, D. and Maurer, M. (2015), "Definition of an Approach for the Development of Product-Service Systems", Procedia CIRP, Elsevier B.V., Vol. 30, pp. 18-23. https://doi.org/10.1016/j.procir.2015.02.130

Neely, A. (2008), "Exploring the financial consequences of the servitization of manufacturing", Operations Management Research, Vol. 1, pp. 103-118. https://doi.org/10.1007/s12063-009-0015-5

Osterwalder, A. Pigneur, Y., Bernarda, G., Smith, A. and Papadakos, T. (2014), Value proposition design, Strategyzer series, Wiley, New Jersey.

Osterwalder, A. and Pigneur, Y. (2010), Business Model Generation, A Handbook for Visionaries, Game Changers, and Challengers, John Wiley \& Sons, Inc., New Jersey.

Pieroni, M., Marques, C., Campese, C., Guzzo, D., Mendes, G. et al. (2016), “Transforming a traditional product offer into PSS: a practical application", Procedia CIRP, Bergamo, Vol. 47, pp. 412-417. https://doi.org/10.1016/j.procir.2016.03.036

Zhang, W., Guo, J., Gu, F. and Gu, X. (2018), "Coupling life cycle assessment and life cycle costing as an evaluation tool for developing product service system of high energy-consuming equipment", Journal of Cleaner Production, Vol. 183, pp. 1043-1053. https://doi.org/10.1016/j.jclepro.2018.02.146

Maiara Rosa, Researcher

University of São Paulo, Department of Production Engineering

400 Trabalhador Saocarlense Ave, 13566590 Sao Carlos, Brazil

Email: maiara.rosa@usp.br 